\title{
Application of Hydrodynamic Cavitation to Improve the Biodegradability of Municipal Wastewater
}

\author{
Magdalena Lebiocka ${ }^{1 *}$ \\ 1 Lublin University of Technology, Faculty of Environmental Engineering, ul. Nadbystrzycka 40B, \\ 20-618 Lublin, Poland \\ e-mail:m.lebiocka@pollub.pl
}

\begin{abstract}
In the present study, the application of hydrodynamic cavitation to improve the biodegradability index of mechanically pre-treated municipal wastewater was examined. The experiments were carried out at the pressure of $3.5,5$, and 7 bar, which was sustained every time in the inlet zone of the cavitation device. As a result, the concentration of soluble chemical and biochemical oxygen demand increased, indicating an effective decomposition and solubilization of complex organic matter. These were accompanied by a visible drop in COD value; in turn, increases in the $\mathrm{BOD}_{5} / \mathrm{COD}$ ratio known as biodegradability index were observed.
\end{abstract}

Keywords: wastewater, hydrodynamic cavitation, biodegradability index, $\mathrm{BOD}_{5} / \mathrm{COD}$ ratio

\section{INTRODUCTION}

The urban and industrial development is responsible for the production of a large quantity of wastewater and thus increases the load of pollutions (Ibrahim et al., 2020). The municipal wastewater includes human excreta, complex organic substances, nutrients, and pathogenic microorganisms. Wastewater also comprises residues of pharmaceuticals as well as detergents, products of personal care, and disinfectants commonly used for domestic activities (Gogate et al., 2020, Sikosana et al., 2020). Due to stringent wastewater and water quality law regulations, the expanded investigation has been focused on developing the processes that are viable and can efficiently deal with toxic and refractory organic pollutants in wastewater and on improving the existing wastewater treatment technologies. Numerous studies were have been conducted to enhance biodegradability and treat municipal wastewater (Korpe et al., 2019). The conventional and commonly known treatment methods of wastewater are not capable to reach complete transformation of the pollutants to water and carbon dioxide, so the development in wastewater treatment methods and technologies is focused to meet the requirements of environmental law (Thanekar and Gogate, 2018). Advanced oxidation processes (AOPs) are the technologies that have been effectively applied for the removal of toxic and refractory contaminants, as a result of uncomplicated reactor construction and the exceedingly efficient operation. The AOP includes the formation of highly reactive hydroxyl radicals $(\cdot \mathrm{OH})$ aimed at the decomposition of contaminants (Dular et al., 2016). Hydrodynamic cavitation is the developing technology that has been investigated by researchers for the water and wastewater treatment and its disinfection, dye removal, cell disruption, delignification of fibrous matter, improvement of protein extraction from soybean and extraction of intracellular biomolecules from the yeast and algae compared to the commonly used conventional methods (Preece et al., 2017, Manusco et al. 2019, Burzio et al., 2020, Yan et al., 2020, Waghmare et al., 2019). Hydrodynamic cavitation is an efficient method that reduces the number of chemical reagents which are necessary for the enhanced treatment process. Therefore, hydrodynamic cavitation as a wastewater and water treatment method does not affect the environment (Dular et al., 2016). Hydrodynamic cavitation allows to efficiency formation of hydroxyl radicals which are responsible 
for contaminant oxidation. During the cavitation process, local hot spots are generated in which imploding gas bubbles cause sudden pressure and temperature growth in the treated medium. Additionally, volatile organic contaminants can infiltrate into the formed cavities which, imploding with high energy can encourage the oxidation process even more effective. The collapse energy of cavitation bubbles is usually applied to destroy the microorganisms and bacteria structures present in wastewater (Bagal and Gogate, 2014, Gągol et al., 2018). The present study examined the advisability of applying the hydrodynamic cavitation of mechanically pre-treated wastewater to improve its biodegradability.

\section{MATERIALS AND METHODS}

\section{Materials}

Municipal wastewater treatment plant "Hajdów" (Lublin, Poland) constituted the source of mechanically pre-treatment wastewater. Nine samples, $35 \mathrm{~L}$ each, were collected from the wastewater and taken directly to the laboratory to conduct the cavitation experiment in triplicate under three different pressure values $(3.5,5.0,7.0$ bar). Upon delivery, the composition of mechanically pre-treatment municipal wastewater was examined and the results were presented in Table 1.

\section{Experimental set-up}

The utilized set-up (closed-loop arrangement) consisted of a centrifugal pump for
Table 1. Characteristics of mechanically pre-treatment municipal wastewater (average values \pm standard deviation)

\begin{tabular}{|c|c|c|}
\hline Parameter & Unit & $\begin{array}{c}\text { Average values } \pm \\
\text { standard deviation }\end{array}$ \\
\hline COD & mg L-1 & $521.02 \pm 18.3$ \\
\hline SCOD & mg L-1 & $457.75 \pm 15.6$ \\
\hline BOD & mg L-1 & $242.38 \pm 14.2$ \\
\hline VFA & mg L-1 & $135.13 \pm 13.7$ \\
\hline Alkalinity & mg L-1 & $544.67 \pm 23.3$ \\
\hline Phenols & $\mathrm{mg} \mathrm{L}-1$ & $2.73 \pm 0.46$ \\
\hline pH & --- & $7.41 \pm 0.17$ \\
\hline
\end{tabular}

pressure generation and a cavitation device that was connected to a circulation tank via pipes. A transparent organic glass tube was installed to enable observing the on-going cavitation; it comprised a steel plate with a conical concentric $3 / 10 \mathrm{~mm}$ orifice (inlet/outlet diameter). The pump was characterized by the following parameters: maximum operating pressure -16 bar, $1000-3000 \mathrm{rpm}$, power rating $-2.2 \mathrm{~kW}$; the output was controlled using a thyristor regulator. The cavitated mixture was driven by the pump - from the $30 \mathrm{~L}$ circulation tank, to the cavitation device and back. The inner diameter of the connecting pipes amounted to $28.76 \mathrm{~mm}$. The employed set-up consisted of the following devices: a manometer (used for measuring the inlet pressure $\mathrm{p} 1)$, control valves, an electromagnetic flow meter $(0.05 \mathrm{~L}$ min-1resolution), as well as piezoelectric pressure gauges (Keller PR-33X, resolution of $1 \mathrm{mbar}$ ) which were connected to a system for digital data measurement (Fig. 1).

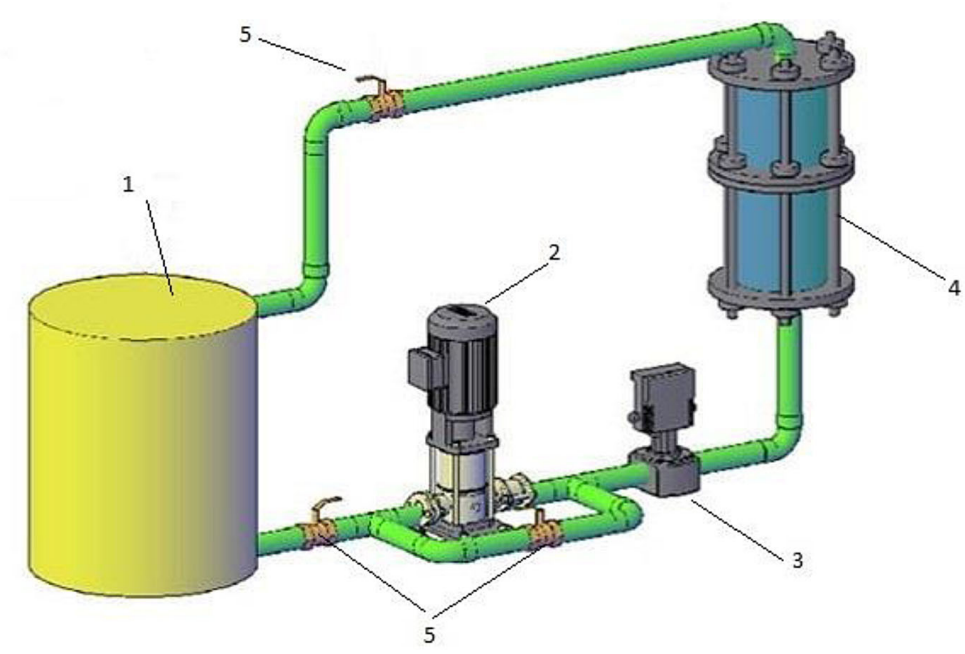

Fig. 1. Scheme of cavitation installation: 1 - circulation tank, 2 - pump, 3 - electromagnetic flow meter, 4 - hydrodynamic cavitation reactor, 5 - valve 
The hydrodynamic cavitation experiment was conducted using an experimental set-up found to be optimal by Montusiewicz et al. (2018).

Hydrodynamic cavitation of wastewater was investigated as a method of improving its biodegradability. The process involved 30 recirculation passes through the cavitation zone at an inlet pressure of 3.5, 5, and 7 bar. The pressure was constantly maintained and controlled using the manometer. The operating time was 60 minutes. The analyses were performed after $2,5,10,30,45$, and 60 minutes. The main objective was to ensure that the biodegradability index is markedly higher than in the case of the uncavitated wastewater.

\section{Composition analysis}

The majority of analyses conducted to determine wastewater composition were performed in accordance with the Polish Standard methods for $\mathrm{BOD}_{5}$ and $\mathrm{pH}$. In turn, a HACH DR 3900 spectrophotometer was used to measure COD, SCOD. An electronic $\mathrm{pH}$ meter was used to establish the $\mathrm{pH}$ value.

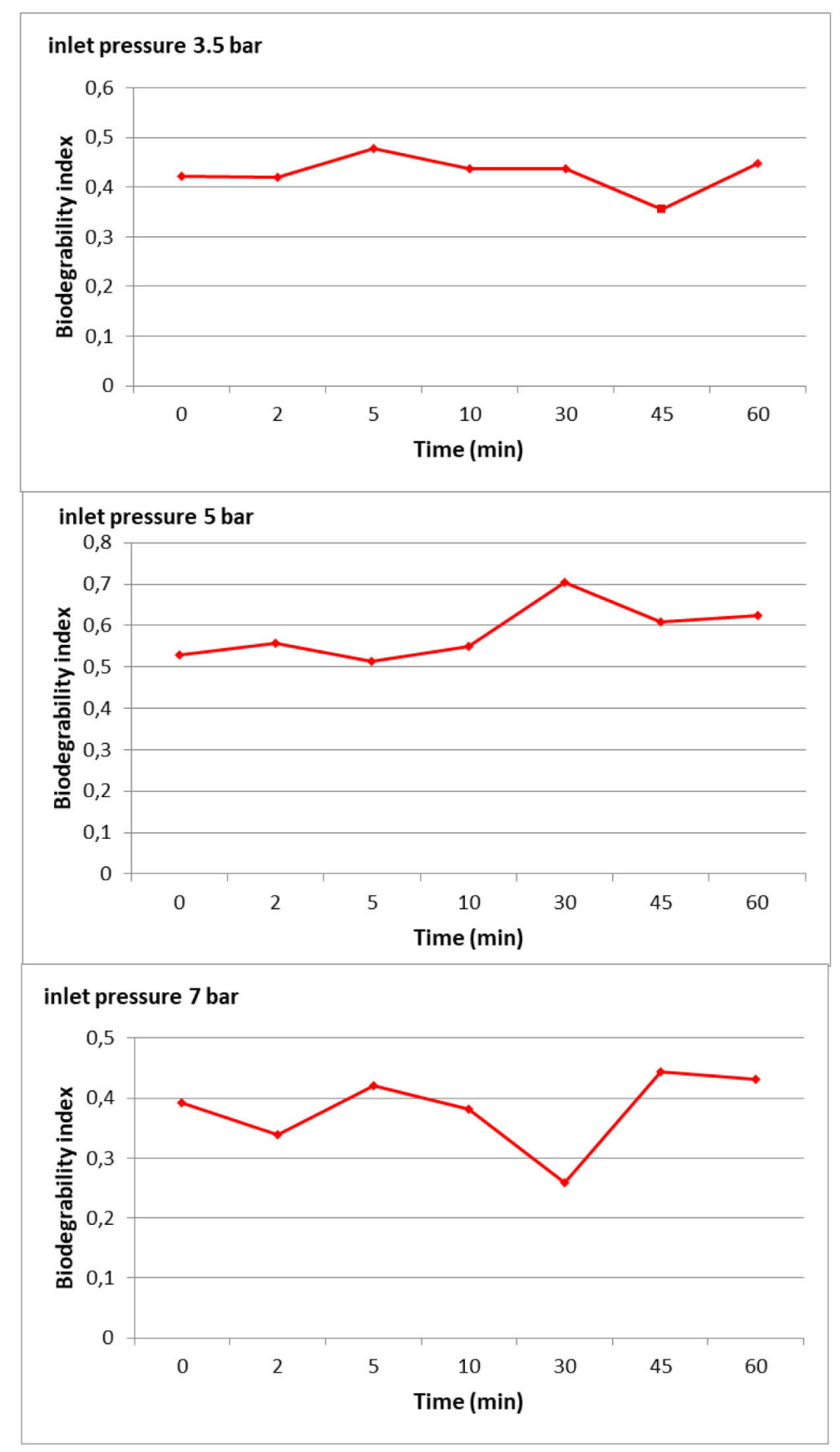

Fig. 2. Changes in $\mathrm{BOD}_{5} / \mathrm{COD}$ ratio during the experiment 


\section{RESULTS AND DISCUSSION}

The results obtained in the present study suggested that cavitation effects varied for the different pressures. The use of hydrodynamic cavitation has contributed to increasing the biodegradability index $\left(\mathrm{BOD}_{5} / \mathrm{COD}\right.$ ratio) of wastewater and may affect the subsequent biological stages of their treatment (Fig. 2).

The use of an inlet pressure of 3.5 bar increased the BI index from 0.42 to 0.48 in the 5 th minute of the process, a similar effect was obtained for the pressure of 7 bar (in the 5th minute of cavitation, the $13 \%$ increase in the BI index was obtained). The highest value of the BI index increase was observed for a pressure of 5 bar in $30 \mathrm{~min}$ of process. The biodegradability ratio increased by $32 \%$, from 0.53 to 0.7 . Similar results were obtained by Padoley et al. (2012) for the enhancement of distillery wastewater biodegradability. They observed that higher inlet pressure (13 bar) provided the maximum value of the $\mathrm{BOD}_{5} / \mathrm{COD}$ rate. Dhanke et al. (2020) used the hydrodynamic cavitation process to treatment fish processing industry wastewater. They observed a significant increase in the BI index, up to 0.93 in the 120-minute duration of the experiment at an inlet pressure of 8 bar. The same researchers applied the hydrodynamic cavitation to treatment vegetable oil refinery wastewater, the biodegradability index in this study reaches the maximum value of 0.69 , and the reduction of
COD was up to $71.8 \%$. These parameters were obtained for an inlet pressure of 8 bar and in $120 \mathrm{~min}$ reaction time (Dhanke and Wagh, 2019). Simpson and Ranade (2018) noted that the cavitation effect depends on many factors like the geometry of the cavitation device and operational parameters. According to Bis et al. (2015) the optimal choice to ensure the enhanced biodegradability index of mature leachate is applying for an orifice plate with a 3/10 mm diameter conical concentric hole. Such a construction of the orifice plate was applied also in this study. Wang and Zhang (2009) noted that there are two basic mechanisms for organic matter degradation by hydrodynamic cavitation. One mechanism is that the organic substances decomposed directly by both high temperature and pressure. The other is the oxidization of $\mathrm{OH}^{*}$ radicals formed by cavitation. Applied in this study the orifice plate with one concentric hole promoted the bubble growth, fast recovery of pressure, and higher cavitation intensity (Simpson and Ranade, 2018). The highest increase of BOD5 from 243 to $379.3 \mathrm{~g} \mathrm{~m}^{-3}$, concomitant with a drop of COD (from 596 to $548.5 \mathrm{~g} \mathrm{~m}^{-3}$ ), was observed for an inlet pressure of 5 bar (Fig. 4), and thus the highest value of the biodegradability index of 0.7 (Fig. 2). At 30 minutes of the experiment, the highest increase in SCOD concentration was also observed from 468.7 to $501 \mathrm{mg} \mathrm{L}^{-1}$.

The increase in $\mathrm{BOD}_{5}$ value and the decrease in $\mathrm{COD}$ for the other considered pressures
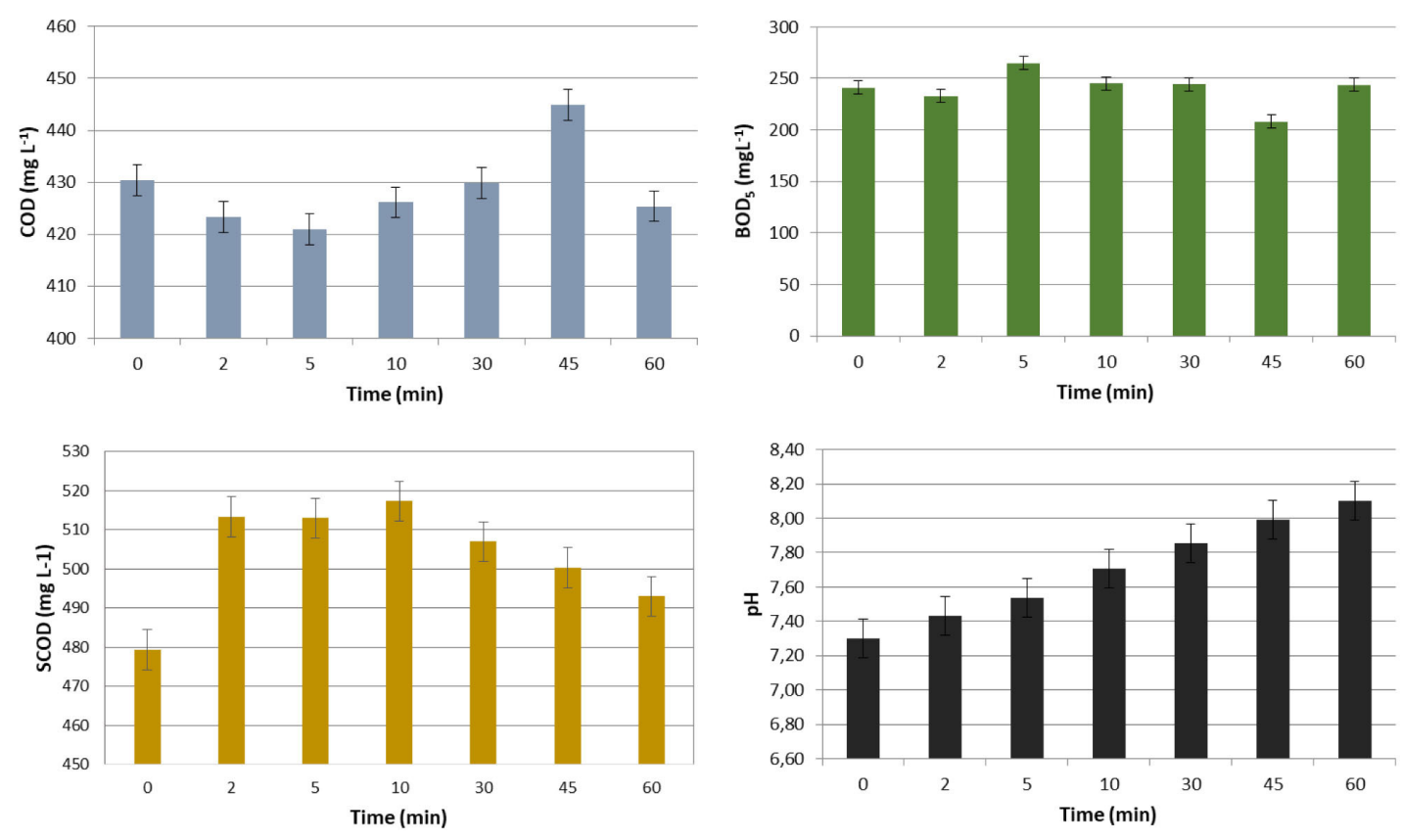

Fig. 3. Changes in $\mathrm{COD}$ and $\mathrm{BOD}_{5}, \mathrm{SCOD}$ and $\mathrm{pH}$ in time at 3.5 bar inlet pressure (the mean values are given, error bars represent the standard error) 

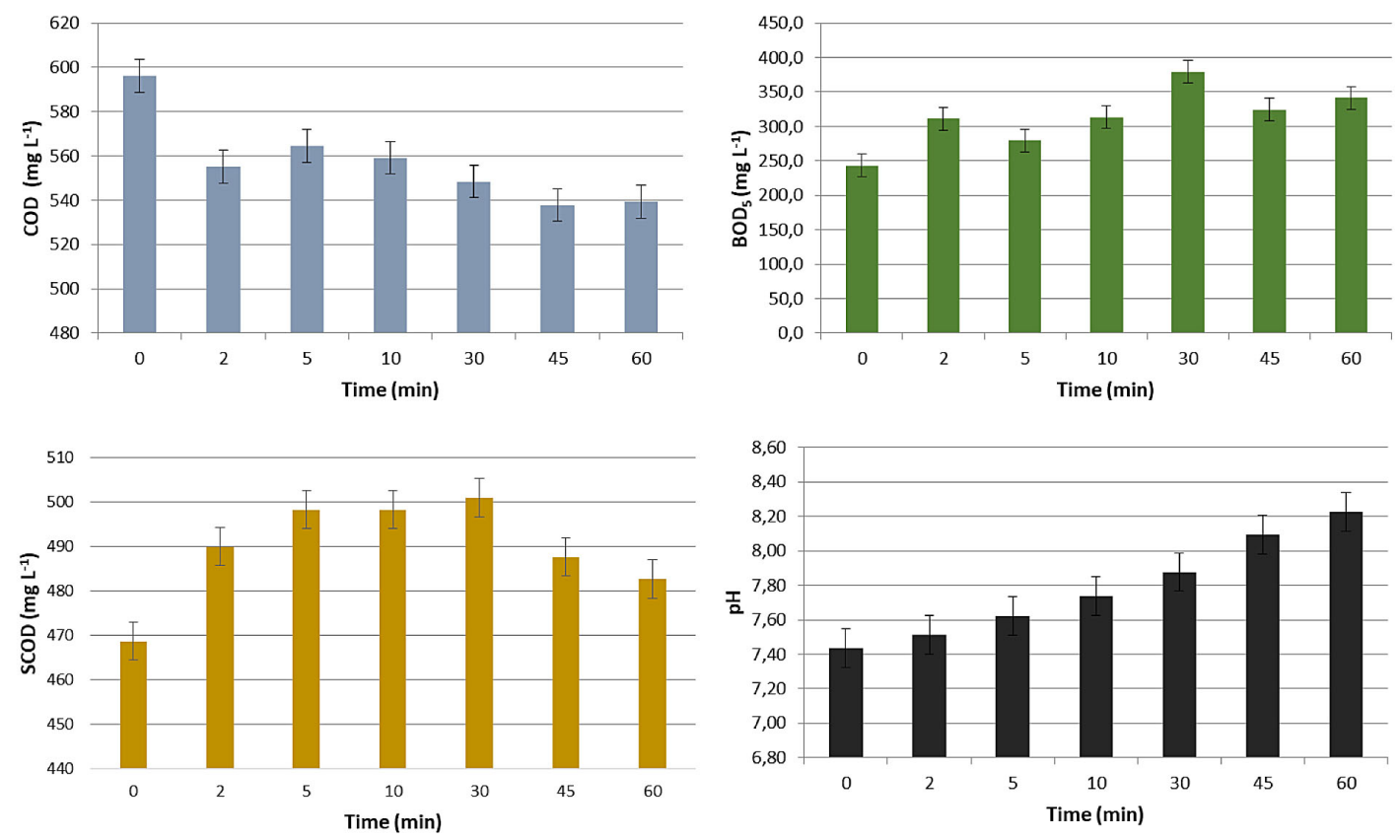

Fig. 4. Changes in $\mathrm{COD}$ and $\mathrm{BOD}_{5}, \mathrm{SCOD}$ and $\mathrm{pH}$ in time at 5 bar inlet pressure (the mean values are given, error bars represent the standard error)

were significantly smaller. At an inlet pressure of 3.5 bar (Fig. 3), the highest value of the biodegradability index of 0.47 was observed in the 5 th minute of running the process and slightly exceeded the value of uncavitated wastewater (0.42). Also during the same time of the process, the highest increase in $\mathrm{BOD}_{5}$ value (from 241 to $264.7 \mathrm{mg} \mathrm{L}^{-1}$ ) and a decrease in COD value (from 430.4 to $421 \mathrm{mg} \mathrm{L}^{-1}$ ) were observed. In the case
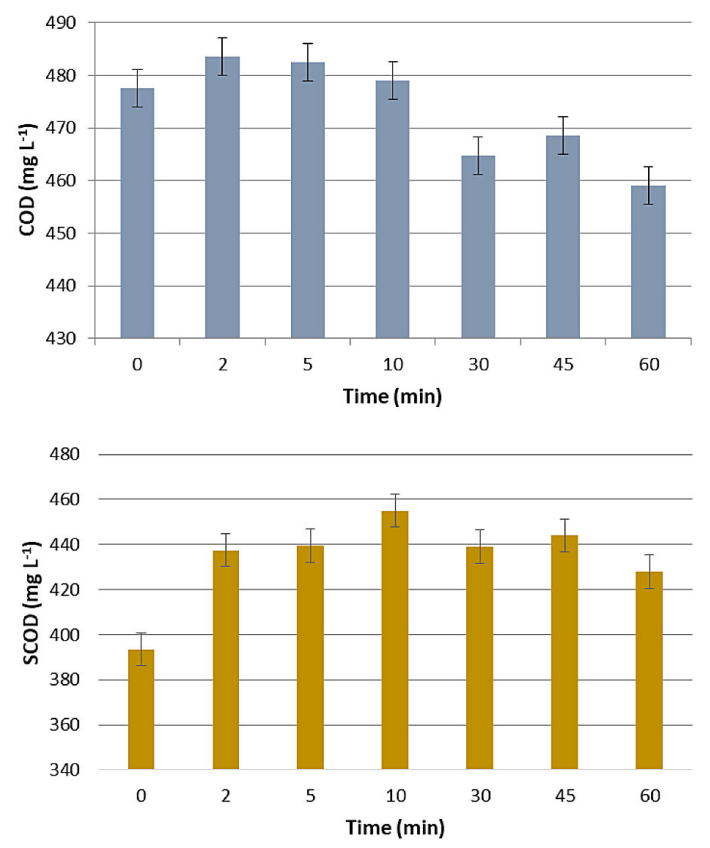

of SCOD, the highest increase (for about $8 \%$ ) was observed in the 10th minute of the experiment. At an inlet pressure of 7 bar (Fig. 5), the highest value of the $\mathrm{BOD}_{5} / \mathrm{COD}$ ratio $(0.44)$ and a $\mathrm{BOD}_{5}$ value increase of around $11 \%$ was observed in $45 \mathrm{~min}$ of the process. Which from an economic point of view is the most unfavorable because the highest inlet pressure and the longest-running time were used. The decomposition of acid groups can
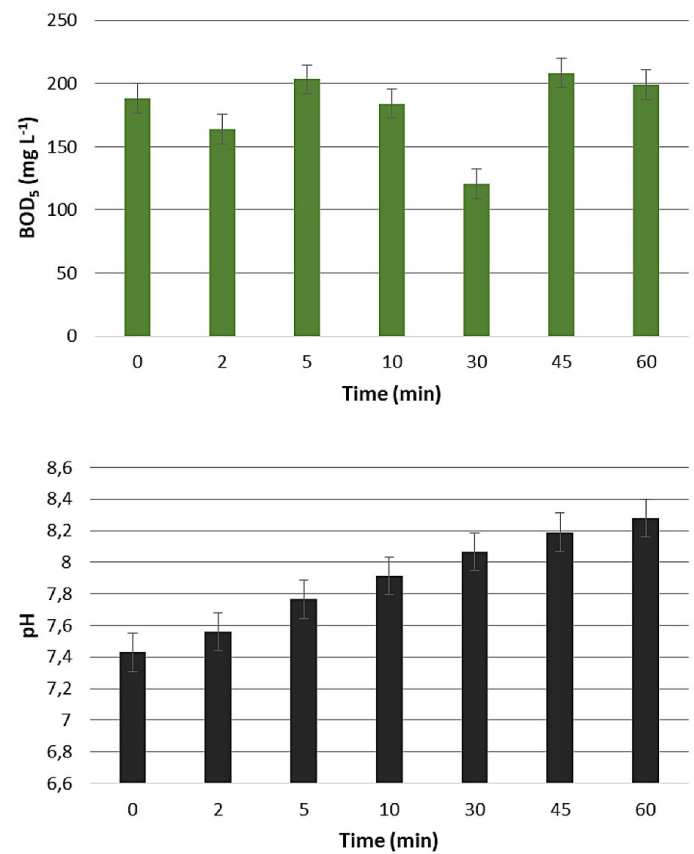

Fig. 5. Changes in $\mathrm{COD}$ and $\mathrm{BOD}_{5}, \mathrm{SCOD}$ and $\mathrm{pH}$ in time at 7 bar inlet pressure (the mean values are given, error bars represent the standard error) 
be confirmed by the $\mathrm{pH}$ changes through the hydrodynamic cavitation process. The wastewater $\mathrm{pH}$ average value was 7.43 and by cavitation, it increased to 8.28. An increase in $\mathrm{pH}, \mathrm{BOD}_{5}$, accompanying with a drop in COD confirmed that the oxidation of the easily biodegradable organic matter, released as the products of the recalcitrant organic compounds degradation, was probably limited due to the presence of antioxidants.

\section{CONCLUSIONS}

Hydrodynamic cavitation of mechanically pretreated wastewater ensured a significant increase in both in $\mathrm{BOD}_{5}$ value and $\mathrm{BOD}_{5} / \mathrm{COD}$ ratio making this medium more available for subsequent biological treatment, optimal effects were obtained with an inlet pressure of 5 bar. Moreover, the concentration of soluble organic compounds expressed as SCOD increased, indicating an effective decomposition and solubilization of complex organic matter.

\section{REFERENCES}

1. Bagal M.V., Gogate P.R. 2014. Wastewater treatment using hybrid treatment schemes based on cavitation and Fenton chemistry: a review. Ultrasonics Sonochemistry. 21, 1-14.

2. Bis M., Montusiewicz A., Ozonek J., PasiecznaPatkowska S. 2015. Application of hydrodynamic cavitation to improve the biodegradability of mature landfill leachate. Ultrasonics Sonochemistry 26, 378-387.

3. Burzio E., Bersani F., Caridi G.C.A., Vesipa R., Ridolfi L., Manes C. 2020. Water disinfection by orifice-induced hydrodynamic cavitation. Ultrasonics Sonochemistry 60, 104740.

4. Dhanke P., Wagh S., Patil A. 2020. Treatment of fish processing industry wastewater using hydrodynamic cavitational reactor with biodegradability improvement. Water Science and Technology doi: https://doi.org/10.2166/wst.2020.049.

5. Dhanke P., Wagh S. 2019. Treatment of vegetable oil refinery wastewater with biodegradability index improvement. Materials Today: Proceedings doi: https://doi.org/10.1016/j.matpr.2019.10.004

6. Dular M.; Griessler-Bulc T.; Gutierrez-Aguirre I.; Heath E.; Kosjek T.; Klemencic A.K.; Oder M.;Petkovsek M.; Racki N.; Ravnikar M., Sarc A., Sirok B., Zupanc M., Zitnik M., Kompare B. 2016.. Use of hydrodynamic cavitation in (waste)water treatment. Ultrasonics Sonochemistry.29, 577-588.

7. Gągol M., Przyjazny A., Boczkaj G. 2018. Wastewater treatment by means of advanced oxidation processes based on cavitation -A review. Chemical Engineering Journal 338, 599-627.

8. Gogate P.R., Thanekar P.D, Oke A.P. 2020. Strategies to improve biological oxidation of real wastewater using cavitation based pre-treatment approaches, Ultrasonics Sonochemistry 64, 105016.

9. Ibrahim S., Azab El-Liethy M., Abia A.L.K., AbdelGabbar M., Mahmoud Al Zanaty A., Mohamed Kamel M. 2020. Design of a bioaugmented multistage biofilter for accelerated municipal wastewater treatment and deactivation of pathogenic mi croorganisms, Science of the Total Environment 703, 134786.

10. Korpe S., Bethi B., Sonawaneb S.H., Jayakumar K.V.2019. Tannery wastewater treatment by cavitation combined with advanced oxidation process (AOP), Ultrasonics Sonochemistry 59, 104723.

11. Mancuso G., Langone M., Andreottola G., Bruni L. 2019. Effects of hydrodynamic cavitation, lowlevel thermal and low-level alkaline pre-treatments on sludge solubilisation. Ultrasonics Sonochemistry 59, 104750.

12. Montusiewicz A., Bis M., Pasieczna-Patkowska S., Majerek D. 2018. Mature landfill leachate utilization using a cost-effective hybrid method. Waste Management 76, 652-662.

13. Padoley K.V.,Saharan V.K., Mudliara S.N., Pandey R.A., Pandit A.B. 2012. Cavitationally induced biodegradability enhancement of a distillery wastewater. Journal of Hazardous Materials 219-220, 69-74.

14. Preece K.E., Hooshyar N.,Krijgsman A.J., Fryer P.J., Zuidam N.J. 2017. Intensification of protein extraction from soybean processing materials using hydrodynamic cavitation. Innovative Food Science and Emerging Technologies 41, 47-55.

15. Sikosana M.L., Sikhwivhilu K., Moutloali R., Madyira D.M. 2019. Municipal wastewater treatment technologies: a review, Procedia Manufactiring 35, 1018-1024.

16. Simpson A., Ranade V.V. 2018. Modelling of hydrodynamic cavitation with orifice: Influence of different orifice designs. Chemical Engineering Research and Design 136, 698-711.

17. Thanekar P., Gogate P. 2018. Application of Hydrodynamic Cavitation Reactors for Treatment of Wastewater Containing Organic Pollutants: Intensification Using Hybrid Approaches, Fluids 3, 98.

18. Waghmare A.,Nagula K., Pandit A., Arya S. 2019. Hydrodynamic cavitation for energy efficient and scalable process of microalgae cell disruption. Algal Research 40, 101496.

19. Wang X., Zhang Y. 2009. Degradation of alachlor in aqueous solution by using hydrodynamic cavitation. Journal of Hazardous Materials 161, 202-207.

20. Yan J., Ai S., Yang F., Zhang K., Huang Y. 2020. Study on mechanism of chitosan degradation with hydrodynamic cavitation, Ultrasonics Sonochemistry doi: https://doi.org/10.1016/j.ultsonch.2020.105046. 